Projections • 15. Practices of Health in Unruly Environments

\title{
Practices of Health in Unruly Environments
}

Andrew Binet Shin Bin Tan

MIT Press

Published on: Oct 26, 2020

DOI: https://doi.org/10.1162/00c13b77.b9ad539e

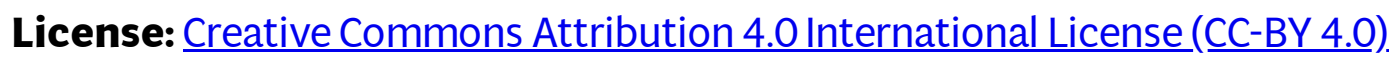




\section{Introduction}

The intersection of health and planning is a burgeoning area of scholarship and practice with the potential to transform both fields in the years to come with emerging health challenges inextricably connected to our environment and how we inhabit it. We all have bodies, we all experience the environment through our bodies, and we all seek to live as well as possible in our bodies wherever we are. Nevertheless, having a body is hard, and it is hard in different ways for different people. These differences and their consequences for individual and collective well-being depend to a large extent on the material conditions of our surroundings, because we literally embody the world around us, as both epidemiologists and medical anthropologists have long argued (Csordas, 1995; Farquhar \& Lock, 2007; Krieger, 2005; Petteway et al., 2019).

Our lived environments - the social, natural, and built worlds around us - are undergoing complex, unpredictable, and disruptive changes that are difficult to control. As these unruly environmental changes become embodied, they produce new forms of health inequity, vulnerability and risk. In the face of changes in the lived environment, actors engage in practices of health that seek to produce healthier human-environment relationships through patterns of activity performed with purpose and intent. Practices of health may be bodily, social, spatial, institutional, and/or professional. They may be carried out by a range of actors, and may span different geographic and temporal scales. These practices seek to produce health through healing, care, survival, joy, hope, justice and/or the prevention of harm. Thus, practices of health range from an individual gathering waste on a local shoreline, to researchers investigating emergent patterns of respiratory disease, to government authorities creating public health policies, to grassroots groups protesting environmental injustice.

For urban planners and practitioners in allied fields, such as public health, who are grappling with how to create healthy human habitats within environments in constant flux, practices of health represent an important area for research and intervention. This volume of Projections explores the theme of practices of health in unruly environments with a specific focus on articulating lessons from already-existing practices of health for practitioners in applied fields such as urban planning and public health. In our call, we solicited papers that investigate one or more practices of health which anticipate or respond to environmental changes across any combination of geographical and temporal scales: from the microbial to the planetary; from the sudden eruption to the imperceptibly slow burn. We urged contributors to explore the implications of their findings for practice, especially in urban planning and public health, and how their findings might be employed in the service of planning for healthy, livable and thriving human environments.

When we first came up with the theme of this volume of Projections in late 2018, we had not anticipated that the world would be roiled in a global pandemic so soon after. Reports of a pneumonia of unknown cause in Wuhan, China, first emerged during the last days of 2019, and has in the short span of months burned across the globe. As we write this in September, 2020, there have been nearly 32 million COVID-19 positive cases, and over 971,000 deaths recorded (The New York Times, 2020). While efforts to stem the spread of COVID- 
19 differ greatly from country to country, state to state, most involve some form of restrictions on human mobility and contact: of international borders, of local businesses, schools, public spaces, care facilities, and many other venues of interaction. These lockdowns have generated tremendous economic and human costs. Global travel and international supply chains have been severely disrupted, businesses have collapsed, and millions of workers, particularly the most vulnerable workers in informal sectors, have been laid off (International Labour Organization, 2020).

While the COVID-19 pandemic seems exceptional in terms of its devastating impact thus far, as well as how it seemed to have caught most of the world off-guard, it is unlikely to be a 'one-off' event to be dealt with and then forgotten. Rather, like the various smaller-scale pandemics that came before it--SARS, MERS, H1N1-COVID-19 exemplifies the 'unruliness' of our modern day environments. Our interconnected world, linked by dense, complex networks of labor, capital and goods, has proven susceptible to the spread of unknown and unpredictable diseases which in turn are being produced by an unprecedented degree of human exploitation of the natural world (Collier \& Lakoff, 2015; Epstein, 2001). The emergence of new pathogenetic zoonoses, including SARS-CoV-2 that caused the current pandemic, has been attributed to the destruction of ecological systems and habitats via aggressive urbanization (Connolly et al., 2020; Decaro \& Lorusso, 2020).

The current responses to COVID19, by actors ranging from international governmental organizations to individuals, also exemplify what it means to live amidst deep uncertainty. Especially during the earlier days of the pandemic, when little was known about the nature of the virus and its transmission, policy-makers had to grapple with decisions whether to impose large-scale quarantines and lockdowns, and how to do so without administering a 'cure' that proves more lethal than the disease itself (Rigby, 2020). On a daily basis, individuals have to balance the uncertain, evolving risks of potential exposure against other clear and pressing needs that require face-to-face interactions. New, virtual ways of living, learning, working and socializing have emerged, for those who are able make this switch, while those who cannot struggle to adapt to the new normal (Guterres, 2020; Lee, 2020; Sekiguchi, 2020; Watts, 2020).

In short, the current pandemic has destabilized and disrupted established patterns of how we inhabit the built environment, and raised challenging new questions about how the built environment can be planned and designed to protect and promote health in the face of emergent threats to health. Planning practice will be challenged to evolve to accommodate and facilitate practices of health across scales that seek salutogenic relationships between bodies and their unruly environments. While Projections 15 does not explicitly revolve around COVID-19, the five papers here each explore a different practice of health that can be adapted to unruly times like these.

\section{Overview of the Papers}

Two papers Uncertain space: Data illusions and the landscape of illness in the $21^{\text {st }}$ century by Sara Carr, and Transdisciplinary synthesis research in unruly environments: Reflecting on a case study of vulnerability \& 
urban fishing in the American Gulf Coast by Lauren Drakopulos, Dustin Robertson, Sarita Panchang, Meghna N. Marjadi, Zach Koehn and Lian Guo, focus on the epistemological aspects of research and analytical practices around understanding the relationship between environment and health.

Sara Carr examines the practice of disease mapping. Her paper shows how early practices of disease mapping were key in guiding decisions around our built environments, and traces the gradual decoupling of illness and environment as mapping techniques modernized. She argues that the decontextualization of disease outbreaks from the physical qualities of landscape and the built environment has facilitated the stigmatization of marginalized places and populations. To remedy this, she calls for new practices of representing disease spatially that accurately represent the complex relationships between present-day built environment and disease, and which maintain an explicit focus on equity.

Lauren Drakopulos and team explore the practice of transdisciplinary research (TR), which considers the complex system of factors that explain an issue's current state, addresses diverse perceptions of an issue from science and society, and sets aside the idealized context of science to produce practical knowledge. They explore how TR can help break down entrenched disciplinary silos in both research and policy, and facilitate better understanding of complex environmental health issues. Through a case study of TR on urban subsistence fishing as a foodway, they present empirically grounded lessons on how to conduct integrated research on the relationships between place-based health, urban development, and environmental equity.

The other three papers in this volume focus on professional practices targeting community health and healthcare provision.

Laura Arpiainen and Johanna Lilius focus their paper, Mobile population based care solutions from Canada and Finland on mobile medical units as a means of healthcare delivery in challenging contexts. They examine two case studies of mobile medical units being deployed: first in the gentrifying downtown of Vancouver, Canada, and second in South Karelia, Finland, a remote area that is facing depopulation. Through these case studies, the authors demonstrate how mobile medical units present an alternative model of care provision emerging in response to urbanization and associated demographic changes that eliminates barriers to access, promotes equity and justice in healthcare delivery, and can help foster self-sufficiency, dignity and independence of communities.

Focusing on cities in Latin America, Marc Krupanski and Sarah Evans investigate a novel practice of community-based harm reduction around drug use, in their paper A right to the city? Harm reduction as urban community development and social inclusion. They argue that traditional harm reduction paradigms, which focus on blood-borne infections and medical interventions, are insufficient to address real and perceived problems around drug use, which truly stem from challenges of spatial representation, social exclusion and marginalization, violence and power, and the struggle for citizenship. The authors argue that due to these root causes, harm reduction approaches based on social inclusion which seek to meet the needs of communities 
most affected by the war on drugs in urban spaces are necessary. They explore one such case of harm reduction carried out through shared social events and workshops, infrastructural improvements, and the creation of spaces for people who use drugs.

Finally, Jason Reece's paper Planning for youth emotional health in unruly environments: Bringing a trauma informed community building lens to therapeutic planning, presents a practice of therapeutic planning that seeks to counteract trauma found in challenging environments. Focusing on a case study of the 'I am My Brother's Keeper' program in Columbus, Ohio, Reese unpacks how Trauma Informed Community Building (TICB) strategies help support the emotional health of youth, through empowerment, radical acceptance, creation of safe spaces, relationship building, mind/body practices and experiential learning.

\section{Reflections on the Papers}

To our delight, the papers we received stretched the concept of 'practices of health' beyond our initial formulation, and helped deepen our understanding of how this concept can function as a lens for understanding how human-environment relationships shape health. Together, the authors of the papers in this volume of Projections explore a range of practices of health -- mapping, fishing, talking, driving, community organizing, harm reduction and of course, researching -- undertaken by actors in different capacities with varying levels of power. Collectively, the papers suggest that the term focuses attention on what people are trying to do in light of changes to or disturbances in their environment, and the challenges they face in their efforts.

Why might this perspective be important for planning? By understanding what actors are trying to accomplish, we might better understand the resources afforded to them by the built environment and how they put them to use in search of better health, as well as the barriers that the environment poses to those actors realizing better health. This, in turn, may help planners identify how to intervene in the built environment to better support or facilitate these actors' efforts to create and improve health. Of course, many actors are trying to accomplish many things in the name of health, and so normative challenges persist: whose practices of health ought we to support, and why? What happens when practices of health come into conflict with one another? Such questions should motivate planners to apply our existing ethical frameworks to questions of health. In doing so, we are likely to realize how and why they merit further development, which will be necessary for planners to hold ourselves accountable to addressing and ameliorating deep health inequities that our discipline has played a significant role in creating and upholding.

The papers in this volume also point to the important ways that practices of health grapple with challenges of representing and understanding the complexity of human-environment relationships. These challenges may be technical and epistemological, as the papers by Carr and Drakopulos et al. indicate: how do we understand and represent this complexity, and how can we trust and act on what we know? Or the challenges may be emotional and psychological, as demonstrated by Reece's research as well as that of Krupanski and Evans: how can we grapple with the trauma that has accumulated over generations of dispossession, and what is planning's role in 
healing wounds we have played a role in perpetrating? These challenges are political, too, as are those raised by Arpiainen and Lilius: as the built environment changes, how do we ensure the health and well-being of those who are left out or left behind? All of these challenges - technical, epistemological, emotional, political are challenges that have been addressed in the planning literature. The question now is not only how to apply that knowledge to questions of health, but how studying health deepens the planning field's understanding of how to grapple with such challenges in ways that are just.

Together, these papers provide two important lessons for researchers working at the intersection of urban planning and public health. First, it is a busy intersection where many avenues of inquiry may fruitfully meet. These papers encourage us as researchers and practitioners to broaden our conception of the relationship between health and planning beyond understanding relationships between the changing features of the built environment and discrete health outcomes. For example, our research might extend to consider how practices undertaken to make sense of the relationship between the built environment and health in one era obscure or limit our understanding in the next. We might seek to understand how the provision of health services for marginalized groups adapts in response to changes in the built environment. Alternatively, we might explore how tools of community development and participatory planning can contribute to efforts to heal from trauma rooted in the social inequalities made durable by plans past. Accordingly, the second lesson is that it will be fruitful for urban planners to collaborate across areas of expertise. In addition to epidemiologists and public health researchers, these papers suggest that those with expertise in fields ranging from history to environmental management, as well as in trauma-informed and harm reduction practices, can offer much to the planning field as we seek to understand how people negotiate changes in their environment in search of better health for themselves and their communities.

Finally, the concept of "practices of health" is useful for planning practitioners in the field because it bridges the fourth wall, so to speak, situating planning alongside any other practice. Planners need to interrogate how planning as a practice of health responds to environmental change - as papers by Carr, Reece, and Drakopulos et al. demonstrate - as well as ensure that we remain accountable to learning from the lessons generated from studying other practices of health. And, indeed, the papers in this volume point to four specific lessons for planning as a practice of health. The first is the importance of overcoming conceptual separations we may maintain between bodies and their environment, and instead beginning with the premise that they are mutually constituted. Next is the importance of attending to emotion, hope and history in understanding what people seek from healthy human-environment relationships. Third is the importance of continuing to develop how we understand and represent the complexity of human-environment relationships, especially in contexts characterized by information, knowledge, or power asymmetries. The final lesson is the importance of continuing to expand planning practice's tolerance for and facility with uncertainty and unknowability, and our ability to continue to work towards health in spite of what we cannot yet understand. 
The COVID-19 pandemic, as an unruly event, has prompted masses to take up new practices of health like masks and social distancing. These practices have, in turn, changed the way that people experience and engage the built environment. It has reinforced the necessity, for urban planners, of understanding the interplay between destabilizing environmental changes and practices of health. It is our hope that this volume of Projections is a valuable resource as our field grapples with our role in the trajectory and aftermath of the pandemic, and continues to try to understand how to create durable foundations for health in the face of evergreater environmental uncertainty.

\section{Acknowledgements}

We are grateful to the authors who contributed to this volume as well as the anonymous reviewers who provided invaluable feedback. We would also like to thank the members of our editorial board for their participation, as well as the team at MIT Press and PubPub for their support during the publication process. Finally, we thank Prof. Erica James, Prof. Mariana Arcaya, and Prof. Larry Vale for their thoughtful guidance.

\section{Editorial Board}

Mariana Arcaya (Massachusetts Institute of Technology)

Xavier de Souza Briggs (New York University)

Jason Corburn (University of California at Berkeley)

Billie Giles-Corti (Royal Melbourne Institute of Technology)

Sandro Galea (Boston University)

Erica James (Massachusetts Institute of Technology)

Mei-Po Kwan (Chinese University of Hong Kong)

Samina Raja (University at Buffalo)

Lawrence J. Vale (Massachusetts Institute of Technology)

\section{References}

Collier, S. J., \& Lakoff, A. (2015). Vital Systems Security: Reflexive Biopolitics and the Government of Emergency. Theory, Culture \& Society, 32(2), 19-51.

https://doi.org/10.1177/0263276413510050

Connolly, C., Ali, S. H., \& Keil, R. (2020). On the relationships between COVID-19 and extended urbanization. Dialogues in Human Geography, 10(2), 213-216.

https://doi.org/10.1177/2043820620934209

Csordas, T. J. (Ed.). (1995). Embodiment and Experience: The Existential Ground of Culture and Self. Cambridge University Press. 
Decaro, N., \& Lorusso, A. (2020). Novel human coronavirus (SARS-CoV-2): A lesson from animal coronaviruses. Veterinary Microbiology, 244, 108693.

https://doi.org/10.1016/j.vetmic.2020.108693

Epstein, P. R. (2001). Climate change and emerging infectious diseases. Microbes and Infection, 3(9), 747754.

https://doi.org/10.1016/S1286-4579(01)01429-0

Farquhar, J., \& Lock, M. (Eds.). (2007). Beyond the Body Proper: Reading the Anthropology of Material Life (1st edition). Duke University Press.

Guterres, A. (2020, June 11). Digital Divide 'a Matter of Life and Death'amid COVID-19 Crisis, Secretary-General Warns Virtual Meeting, Stressing Universal Connectivity Key for Health, Development. UN. https://www.un.org/press/en/2020/sgsm20118.doc.htm

International Labour Organization. (2020). ILO Monitor: COVID-19 and the world of work. Sixth edition. (p. 25) [Briefing note]. International Labour Organization.

Krieger, N. (2005). Embodiment: A conceptual glossary for epidemiology. Journal of Epidemiology \& Community Health, 59(5), 350-355. https://doi.org/10.1136/jech.2004.024562

Lee, J. Y. (2020, August 5). The South Koreans left behind in a contact-free society. BBC News. https://www.bbc.com/worklife/article/20200803-south-korea-contact-free-untact-society-after-coronavirus

Petteway, R., Mujahid, M., \& Allen, A. (2019). Understanding Embodiment in Place-Health Research: Approaches, Limitations, and Opportunities. Journal of Urban Health, 96(2), 289-299. https://doi.org/10.1007/s11524-018-00336-y

Rigby, J. (2020, June 5). Is the cure worse than the disease? The hidden harms of the Covid-19 lockdowns. The Telegraph. https://www.telegraph.co.uk/global-health/science-and-disease/cure-worse-disease-hidden-harmscovid-19-lockdowns/

Sekiguchi, W. (2020, April 15). COVID-19 pandemic prompts a digital revolution. The Japan Times. https://www.japantimes.co.jp/opinion/2020/04/15/commentary/japan-commentary/covid-19-pandemicprompts-digital-revolution/

The New York Times. (2020). Covid World Map: Tracking the Global Outbreak. The New York Times. https://www.nytimes.com/interactive/2020/world/coronavirus-maps.html

Watts, G. (2020). COVID-19 and the digital divide in the UK. The Lancet Digital Health, 2(8), e395-e396. https://doi.org/10.1016/S2589-7500(20)30169-2 